\title{
Formation of skin-core in carbon fibre processing: A defect or an effect?
}

\author{
S. Nunna ${ }^{1}$, M. Setty ${ }^{1}$, M. Naebe $e^{1,2^{*}}$ \\ ${ }^{1}$ Deakin University, Geelong, Carbon Nexus, Institute for Frontier Materials, 3216 Victoria, Australia \\ ${ }^{2}$ School of Engineering, Edith Cowan University, Western Australia, 6027 Joondalup, Australia
}

Received 22 June 2018; accepted in revised form 10 September 2018

\begin{abstract}
The influence of stabilized fibre structure and skin-core formation induced by rapid thermal stabilization of polyacrylonitrile (PAN) on the tensile properties of carbon fibres was investigated. Three sets of samples were prepared by stabilizing PAN fibres under three temperature profiles using a continuous carbon fibre processing line. Initially, the chemical structure and density variations in stabilized fibres were examined with respect to process conditions using Fourier Transform Infrared Spectroscopy (FTIR) and density column methods. Interestingly, while the cyclization and dehydrogenation indices are similar for all the stabilized fibres irrespective of temperature profiles used, the densities of these fibres varied from 1.34 to $1.366 \mathrm{~g} / \mathrm{cc}$. Micro-Raman studies showed the existence of structural heterogeneity in the fibres from low temperature $(L T)$ carbonization $(I(D) / I(G)$ ratio of core was $\sim 5.6 \%$ higher than the skin) that eventually reduced with high temperature $(H T)$ carbonization because of uniform $\mathrm{sp}^{3}$ to $\mathrm{sp}^{2}$ hybridization of carbons. However, modulus mapping revealed heterogeneous storage modulus distribution in the HT carbon fibre cross-section from Trial-2 (storage modulus of core was $\sim 23 \mathrm{GPa}$ less than the skin). Interestingly, this heterogeneity did not show a significant effect on the bulk properties of carbon fibres suggesting skin-core formation is an effect rather than a defect.
\end{abstract}

Keywords: mechanical properties, carbon fibres, industrial applications, processing technologies, material testing

\section{Introduction}

In the past few decades there has been an ever growing interest in carbon fibre materials research due to their ability in providing light-weight solutions in multidisciplinary applications associated with automobiles, aerospace, wind energy, sports and defence [1-3]. Despite various advantages, according to industry experts these materials are not received overwhelmingly from the mass vehicle markets as expected because of their expensive nature [4]. Nowadays, research has been focused on understanding various materials and processes involved in manufacturing and identifying pathways to reduce the overall cost of carbon fibres. For instance, researchers have made an attempt to use alternative low-cost precursor materials such as lignin [5-8], textile grade acrylic fibres [9], cellulose [10, 11] and coal [12] for processing carbon fibres. However, this research is still in the early stages and the carbon fibre properties obtained are inferior to Polyacrylonitrile (PAN) based carbon fibres.

Currently, more than $90 \%$ of the commercial carbon fibres are processed from PAN fibres because of their ability in producing carbon fibres with high tensile properties along with high carbon yield [13, 14]. Generally, carbon fibres are manufactured by processing PAN fibres in various stages such as 1 . Thermal stabilization in air at temperatures ranging from 200 to $300{ }^{\circ} \mathrm{C}[15] 2$. Carbonization of thermally stabilized fibres in nitrogen at temperatures between 300 and $2800^{\circ} \mathrm{C}$ depending on the application [16]. In the process chain from PAN precursor fibres until their 
conversion to carbon fibres, stabilization is considered to be the most time and energy expensive stage [17]. It takes around 100 to 200 min to thermally stabilize PAN fibres before proceeding to carbonization [18]. Moreover, apart from precursor quality, thermal stabilization of PAN fibres plays a critical role in defining the resultant carbon fibre properties [19-21].

During thermal stabilization, PAN fibres undergo various physical and chemical transformations and attain thermal stability [22]. This thermally induced structural conversion in PAN fibres is an exothermic process and involves three major reactions; 1 . Cyclization 2. Dehydrogenation and 3. Oxidation which transform PAN polymer structure from linear to ladder structure [23]. Temperature, time and tension are considered to be the critical parameters which should be balanced during thermal stabilization in order to control the structural evolution and the quality of stabilized fibres [24]. Recently, various researchers focussed on controlling the exothermic nature of PAN fibres in order to improve its ability to stabilize under low temperatures and reduce the energy consumption in this process through the addition of various comonomers $[18,25]$, pre-treating the fibres with chemicals including ionic liquids [26] and ammonium iron (II) sulphate [27]. It was identified that the use of various combinations of co-monomers in PAN fibres are beneficial in broadening the temperature range of the exothermic heat release of respective fibres and also assist in attaining thermal stability at lower temperatures $[18,25]$. However, these studies are confined to lab scale and have not demonstrated their influence on resultant carbon fibre properties. On the other hand, the studies associated with chemical treatment is mainly confined to the stabilization stage rather than presenting the potential final benefits through subsequent carbon fibre properties. Moreover, pre-treating with chemicals may cause cosmetic damage to filaments and also could lead to fusing of filaments when exposed to temperatures due to the lack of exothermic heat dissipation from fibre surface through filament shaking.

In the recent past, studies were conducted to understand the thermal stabilization process using established commercial PAN fibres [20, 28-30], however, only few researchers worked on continuous carbon fibre processing where it involves stepwise stabilization close to the industrial manufacturing process [1, $31,32]$. Nonetheless, up to our knowledge most of the works are confined to thermal stabilization rather than identifying the influence of process variations in this stage on subsequently processed carbon fibres. From the economy's point of view, it is always attractive to use high temperatures in stabilization to speed up the process and increase the production rates [29]. However, it is believed that processing the fibres at high temperature profiles could lead to uncontrolled exothermic reactions and finally affect the quality of fibres [29]. Hence, systematic decisions have to be made before choosing the temperature profiles. Moreover, treating the fibres at high temperatures leads to the evolution of skin-core or radial structural heterogeneity in fibres due to a combination of delay in diffusion of oxygen into the fibre core and lack of dissipation of exothermic heat from the fibre core [33, 34]. It is proposed that processing the stabilized fibres with skin-core would lead to structural defects and finally could affect the properties of the resultant carbon fibres [35]. Recently, researchers used various advanced characterization techniques such as NanoDMA, Transmission Electron Microscopy (TEM), Micro-Raman and Micro$\mathrm{X}$-ray diffraction for understanding the structure and property differences in the cross-section of carbon fibres [36-39]. Nevertheless, it is challenging to identify the evidence regarding the relationship between the skin-core evolution during carbon fibre processing and its effect on final tensile properties of carbon fibres. Based on our understanding it is essential to build a relationship between rapid processing during thermal stabilization and its influence on cross-sectional properties, structure evolution and bulk tensile properties of resultant carbon fibres. Proceeding with this study possibly provides a pathway to improve the throughput and reduce the cost of carbon fibres.

Hence, in the current study we made an attempt to process and characterize three sets of fibre samples at three different stabilization conditions by maintaining common carbonization process parameters using a continuous carbon fibre processing line. Initially, chemical structure and density variations between the samples from each stage of thermal stabilization were assessed with respect to three temperature profiles. Later on, the cross-sectional structure and properties of resultant low temperature and high temperature carbonized fibres were examined. Finally, properties of carbon fibres with respect to stabilized fibre structure and the presence of skin-core were examined. 


\section{Experimental}

\subsection{Precursor and sample preparation}

A commercial PAN precursor fibre (diameter $\sim 13 \mu \mathrm{m}$ ) tow of size $24 \mathrm{k}$ from BlueStar Co Ltd, China, the composition of the precursor is believed to be acrylonitrile (93 wt\%), methyl acrylate (6 wt $\%$ ) and itaconic acid (1 $\mathrm{wt} \%)$ [20]. The fibre was processed using a research scale continuous carbon fibre processing line at Carbon Nexus, Deakin University, Australia. The schematic of the carbon fibre line has already been presented in our earlier work [1]. The research line consists of four stabilization ovens, low temperature furnace and high temperature furnace. PAN fibre samples were thermally stabilized using three temperature profiles and further carbonized under similar conditions. The process conditions used for stabilization are listed in Table 1. A maximum temperature of approximately $800^{\circ} \mathrm{C}$, tension $\sim 1900 \mathrm{cN}$ and a dwell time of $\sim 6$ min were used in low temperature $(L T)$ carbonization and in high temperature (HT) carbonization a maximum temperature of approximately $1400^{\circ} \mathrm{C}$, tension $\sim 2400 \mathrm{cN}$ and a dwell time of $\sim 4$ min were used to process carbon fibres. Samples were collected at the end of each zone in stabilization, at the end of low temperature (Baseline fibre diameter: $\sim 9.2 \mu \mathrm{m}$ ) and high temperature carbonization (Baseline fibre diameter: $\sim 8.1 \mu \mathrm{m}$ ) for further analysis.

\subsection{Density measurements}

The fibre sample density was obtained using a double density gradient column apparatus from Lloyd Instruments Ltd which was maintained at $23^{\circ} \mathrm{C}$. The first column consists of a mixture of calcium nitrate $(2.36 \mathrm{~g} / \mathrm{cc})$ and distilled water solution used to obtain densities of precursor and stabilized fibres. The second column was filled with 3-ethylphosphate $(1.072 \mathrm{~g} / \mathrm{cc})$

Table 1. Process parameters for thermal stabilization of PAN precursor fibres.

\begin{tabular}{|c|c|c|c|c|c|}
\hline \multicolumn{6}{|c|}{ Stabilization process parameters } \\
\hline Sample & Zone-1 & Zone-2 & Zone-3 & Zone-4 & \\
\hline \multirow{3}{*}{ Baseline } & 227 & 237 & 248 & 258 & Temperature $\left[{ }^{\circ} \mathrm{C}\right]$ \\
\hline & $\sim 2400$ & $\sim 2600$ & $\sim 2700$ & $\sim 3000$ & Tension \\
\hline & 20 & 20 & 20 & 20 & Time \\
\hline \multirow{3}{*}{ Trial-1 } & 237 & 248 & 258 & & Temperature $\left[{ }^{\circ} \mathrm{C}\right]$ \\
\hline & $\sim 2600$ & $\sim 2700$ & $\sim 3000$ & & Tension \\
\hline & 20 & 20 & 20 & & Time \\
\hline \multirow{3}{*}{ Trial-2 } & 237 & & 258 & & Temperature $\left[{ }^{\circ} \mathrm{C}\right]$ \\
\hline & $\sim 2600$ & & $\sim 3000$ & & Tension \\
\hline & 20 & & 20 & & Time \\
\hline
\end{tabular}

and 1,3-dibromopropane $(1.99 \mathrm{~g} / \mathrm{cc})$ solution used to attain densities of low and high temperature carbon fibres. Samples were prepared by making a knot and pre-wetted in the light density solution and released gently into respective columns using tweezers and allowed them to reach a stable position for at least 5 hours. The sample heights were noted down along with the standard floats in the column. Finally density of the samples was calculated using Equation (1):

Density $=\rho f_{1}+\frac{\left(h f_{1}-h_{\mathrm{s}}\right)\left(\rho f_{2}-\rho f_{1}\right)}{h f_{1}-h f_{2}}$

where ' $\rho f_{1}$ ', ' $\rho f_{2}$ ', $h f_{1}$ ' and ' $h f_{2}$ ' denotes floats densities and heights located above and below the sample and ' $h_{\mathrm{s}}$ ' is the sample height.

\subsection{FTIR studies}

Fourier Transform Infrared (FTIR) spectroscopy was performed on the fibre samples using a Bruker Lumos FTIR machine equipped with germanium crystal $\left(n_{\mathrm{Ge}}=4\right)$ in Attenuated Total Reflectance (ATR) mode. The FTIR absorbance spectra were acquired between wave numbers 600 to $4000 \mathrm{~cm}^{-1}$ at a resolution of $4 \mathrm{~cm}^{-1}$. Each spectrum is a representation of $64 \mathrm{co}-$ added scans. At least three repetitions were conducted for each fibre sample. The progress in cyclization and dehydrogenation reactions were obtained using Equations (2) and (3) [34, 40, 41]:

Cyclization index $=$

$$
=\frac{0.29 \cdot A b s(1595)}{A b s(2243)+0.29 \cdot A b s(1595)}
$$

Dehydrogenation index $=\frac{A b s(1366)}{A b s(1454)}$

where $A b s(1595)$ is the peak intensity associated with the formation of cyclic structures at wavenumber (1590-1595 $\left.\mathrm{cm}^{-1}\right), A b s(2243)$ is the peak intensity of unreacted nitrile groups at $\left(2233-2245 \mathrm{~cm}^{-1}\right)$, $A b s(1360)$ is the peak intensity of $\mathrm{CH}$ functional groups at $\left(1360-1370 \mathrm{~cm}^{-1}\right)$ and $A b s(1454)$ is the peak intensity of $\mathrm{CH}_{2}$ functional groups at (1442$\left.1454 \mathrm{~cm}^{-1}\right)$ in the absorbance spectra [34].

\subsection{Tensile properties}

The tensile testing on at least 50 single filaments of each carbon fibre sample was conducted using a Textechno Favimat. A gauge length of $25 \mathrm{~mm}$, a pretension of $0.5 \mathrm{cN}$ and a test speed of $2 \mathrm{~mm} / \mathrm{min}$ were considered for these measurements. 


\subsection{Micro-Raman studies}

Reinshaw Invia Raman micro spectrometer with $488 \mathrm{~nm}$ argon laser was used to obtain Raman spectra from the cross-section of carbon fibre samples. Calibration was conducted on silicon wafer prior to spectral acquisition. Samples for this analysis were prepared by carefully mounting carbon fibres in epoxy, grounded and polished up to $1 \mu \mathrm{m}$ precision. Spectra from fibre cross-sections were obtained in line scan mode using an objective of $100 \times$ and a numerical aperture of 0.9 . At least 7 spectra were acquired across the fibre diameter with a step size of $1 \mu \mathrm{m}$, laser spot size of approximately $660 \mathrm{~nm}$. The parameters for this spectral acquisition include laser power (10\%), accumulations (10) and exposure time $(5 \mathrm{~s})$. At least spectra from 5 specimens from each fibre sample set were collected and post processed using Origin software for baseline correction and further analysed.

\subsection{Modulus mapping}

Nanoscale modulus mapping was performed on the fibre cross-sections using a Hysitron, Triboindenter (TI 950) machine which was equipped with Berkovich diamond indenter, force modulation system, lock in amplifier and piezo scanner. This is a unique technique that simultaneously scans and quantitatively maps mechanical properties of a material at a high spatial resolution. Each pixel in the image can be quantified as a representative property of a material [42]. In order to conduct this analysis, we have used the same samples as described in Section 2.5. The procedures followed and setting parameters used in this study can be found in the literature [36, 43]. At first a small static contact normal force of $2 \mu \mathrm{N}$ was applied to scan the area of interest on the sample surface using a Piezo scanner. Later on it was superimposed with a dynamic force of $2 \mu \mathrm{N}$ at a frequency of $200 \mathrm{~Hz}$. Scanning was performed on an area of $20 \times 20 \mu \mathrm{m}^{2}$ at a scan rate of $0.1 \mathrm{~Hz}$. The response related to displacement amplitude and its phase shift with the applied periodic force was obtained by a lock in amplifier [42]. These values were further utilised to obtain modulus mapping over the given area using a 'Triboscan - modulus mapping' software.

\section{Results and discussion}

\subsection{Influence of temperature profile on structure and property evolution in stabilized fibres}

Chemical structure evolution in fibres from each zone of the stabilization stage was assessed using FTIR studies. Figure 1a shows an example spectra of baseline samples from each stabilization zone and indicated with the peaks corresponding to various functional groups. In PAN precursor fibres predominant peaks are at $2243,1730,1450$ and $2932 \mathrm{~cm}^{-1}$ which are associated with stretching of unreacted nitrile groups, stretching of carbonyl groups in comonomers and in-plane bending and stretching of $\mathrm{CH} 2$ functional groups, respectively [44]. New functional groups started to appear after exposure to temperatures.

The absorbance peaks at approximately 1590, 1366, 806 and $1660 \mathrm{~cm}^{-1}$ indicates the formation of a combination of $\mathrm{C}=\mathrm{C}, \mathrm{C}=\mathrm{N}$ and $\mathrm{N}-\mathrm{H}, \mathrm{CH},-\mathrm{C}=\mathrm{CH}$ and $\mathrm{C}=\mathrm{O}$ in conjugated ketones $[34,44]$, respectively, in the polymer molecular structure with the progress of thermal stabilization. It is also an indication of evolution of ladder structure in fibres [34]. The development of these functional groups is associated with mainly three reactions; cyclization of nitrile groups, dehydrogenation and oxidation [28, 34].

The progress of thermal stabilization in fibres with respect to three temperature profiles is quantitatively analysed by calculating cyclization and dehydrogenation indices using the Equations (2) and (3). Figure $1 \mathrm{~b}$ and $1 \mathrm{c}$ shows the trends of cyclization and dehydrogenation indices with respect to treatment temperatures. There is an overall improvement in the progress of stabilization in all the fibre samples with an increase in treatment temperatures. However, progress of cyclization reaction in fibres corresponding to Trial- 1 and Trial-2 samples treated at $237^{\circ} \mathrm{C}$ showed at least $16.8 \%$ lower than the baseline samples due to prior treatment of baseline samples at $227^{\circ} \mathrm{C}$ for $20 \mathrm{~min}$. However, at higher temperatures this difference is reduced and all the fibres showed approximately 0.68 to 0.69 cyclization index at $258^{\circ} \mathrm{C}$. With an initial exposure to temperatures, segmental mobility of nitrile groups assists in building strong dipole interactions between them in the amorphous phase of fibres, however, with further rise in temperatures, these dipole interactions weaken and 

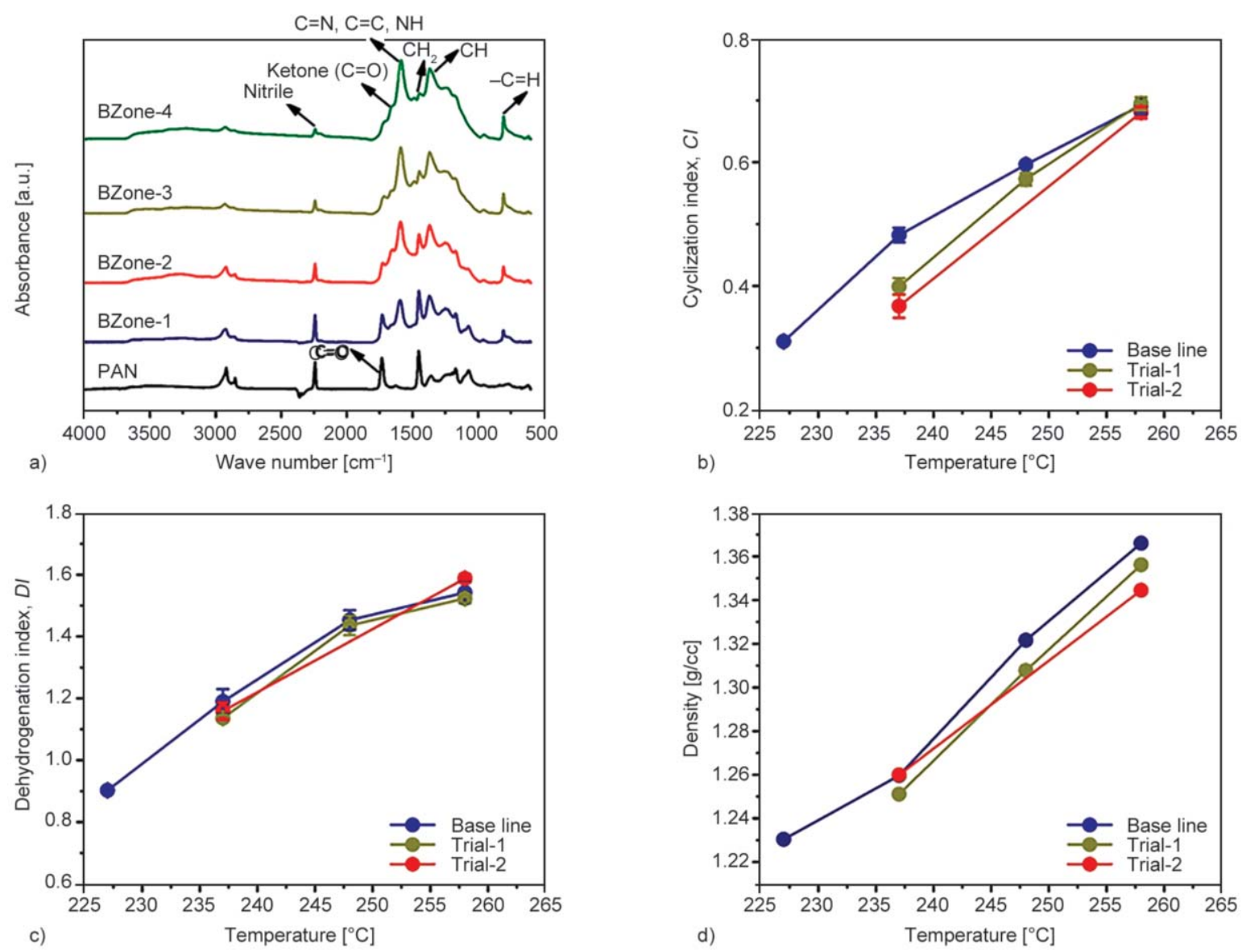

Figure 1. Chemical structure and property evolution in fibres with respect to treatment temperature a) an example FTIR spectra of baseline samples b) cyclization index c) dehydrogenation index d) fibre density.

nitrile groups will start participating in the cyclization reaction and leads to the formation of ladder polymer structure [45]. In the baseline sample, some of the nitrile groups already experienced the initial phase of this process and participated in the cyclization reaction at $227^{\circ} \mathrm{C}$ before proceeding to subsequent temperatures, hence less effort is required to achieve higher extent of cyclization at $237^{\circ} \mathrm{C}$ compared to the other samples. Moreover, in the other samples most of the energy in the initial stage must have been utilised to bring the nitrile groups into appropriate positions to make them participate in the cyclization reaction. However, in the later stages of stabilization, the participation of nitrile groups in the cyclization reaction has been driven by treatment temperature, hence all the samples registered similar cyclization index values. On the other hand irrespective of the difference in temperature profiles, all the samples showed similar dehydrogenation index between $\sim 1.13$ and $\sim 1.58$. Oxygen absorption in fibres is temperature driven and it assists in promoting a dehydrogenation reaction through the elimination of hydrogen in the form of $\mathrm{H}_{2} \mathrm{O}[19,44,46]$. Hence, in the current scenario irrespective of prior treatment all the fibres showed a similar dehydrogenation index.

The density of fibre samples increased with increase in treatment temperature as shown in Figure 1d. The final fibre densities at $258^{\circ} \mathrm{C}$ for Baseline, Trial- 1 and Trial-2 samples are 1.366, 1.356 and $1.344 \mathrm{~g} / \mathrm{cc}$, respectively. This increase in density compared to PAN fibres ( $\sim 1.18 \mathrm{~g} / \mathrm{cc}[34])$ is attributed to the development of a compact structure with the progress of stabilization reactions. Considering Figure 1d, the density of the Baseline sample is higher than the other samples even though at final stabilization temperature both cyclization and dehydrogenation indices (Figure $1 \mathrm{~b}$ and $1 \mathrm{c}$ ) are similar for all the samples. In view of the temperature profiles used, rapid thermal treatment of the samples from Trial-1 and Trial-2 could have led to chain scission and finally affected the evolution of denser structures in fibres.

It has been well defined in the past that it is important to maintain stabilized fibre density ideally between 1.34 and $1.39 \mathrm{~g} / \mathrm{cc}$ in order to obtain carbon fibres with high tensile strength [47]. In the current scenario sample densities from Baseline to Trial-2 
are within the ideal suggested range. At the same time, since Trial-2 fibres were processed under larger temperature steps compared to the other two samples (Baseline and Trial-1) there is a possibility of radial heterogeneity/ skin-core development in these fibres as mentioned earlier [34]. These two arguments raise interest in analysing the cross-sectional and bulk tensile properties of the resultant carbon fibres.

\subsection{Influence of stabilization conditions on the evolution of cross-sectional structure and properties of resultant carbon fibres}

The evolution of cross-sectional microstructure and properties of resultant carbon fibres with respect to various temperature profiles in stabilization is presented in this section. Figure 2a shows an example of data collection points across the fibre diameter. An example Raman spectrum from one of the carbon fibre samples presented in Figure 2b, shows mainly two peaks which are recognised as $D$-peak $(\sim$ at $\left.1360 \mathrm{~cm}^{-1}\right)$ and $G$-peak $\left(\sim\right.$ at $\left.1590 \mathrm{~cm}^{-1}\right)$ [33]. $D$-peak is associated with $A_{1 \mathrm{~g}}$ vibrational mode of a graphitic plane having a structural disorder or defect sites and commonly present in poorly graphitized fibres whereas $G$-peak is associated with in-plane stretching of $\mathrm{sp}^{2}$ hybridized carbon pairs which have $E_{2 \mathrm{~g}}$ symmetry $[48,49]$. The relative variation of these two peaks helps in quantifying the structural disorder in the microstructure of carbon fibres.

Figure 2c shows the ratio of the intensities of $D$ and $G$ peaks of the Raman spectra extracted across the fibres from LT and HT carbonization furnaces. Overall, fibres showed higher intensity ratios compared to HT fibres. Moreover, there is no structural difference observed between the fibre samples from both LT and HT with respect to the temperature conditions used in the thermal stabilization process. This indicates that the structural transformations in the fibres is consistently associated with the treatment temperatures at specific stages rather than relying on the previous thermal treatments. Interestingly, all the fibres from the LT furnace displayed parabolic trends
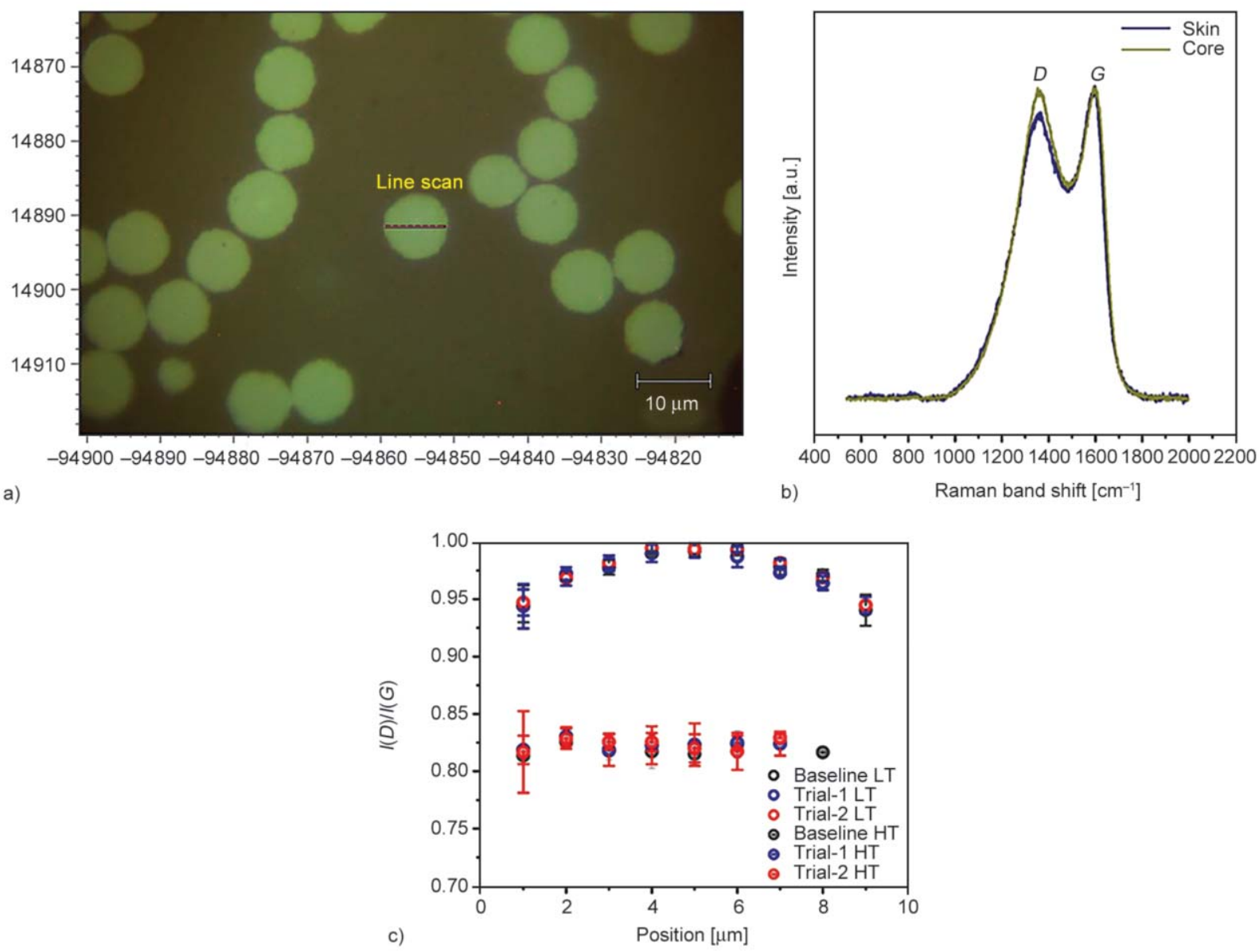

Figure 2. Raman spectroscopy analysis on fibre samples a) a representation of line scan across the fibre cross-section, b) an example Raman spectra of LT carbon fibre sample normalised to $G$-band, c) $I(D) / I(G)$ ratios calculated from Raman spectra for all the samples. 
of $I(D)$ and $I(G)$ ratio indicating the presence of skincore differences where the skin had highly ordered structures compared to the core. $I(D)$ and $I(G)$ ratio of the fibre core region is at least $5.6 \%$ higher than the skin region. However, this difference is not evident in the samples from the HT furnace.

During carbonization in an inert atmosphere, loss of heteroatoms such as oxygen, hydrogen and nitrogen takes place from fibres in the form of $\mathrm{H}_{2} \mathrm{O}, \mathrm{NH}_{3}, \mathrm{~N}_{2}$, $\mathrm{H}_{2}, \mathrm{CH}_{4}$ and $\mathrm{HCN}$ with the progress of a crosslinking mechanism between ladder structures and the formation of planar structures [50]. Fitzer et al. [50] mentioned that the rapid loss of nitrogen from fibre structures takes place at higher temperatures above $700{ }^{\circ} \mathrm{C}$. Moreover, Mittal et al. [51]. stated that the loss of nitrogen from fibres takes place at temperatures between 600 and $1000^{\circ} \mathrm{C}$, however, de-nitrogenation in the skin or surface regions starts at earlier temperatures in the range of 600 to $800^{\circ} \mathrm{C}$ compared to inner regions of the fibres [51]. Hence, it can be derived that the formation of planar structures in the surface regions of fibres is more advanced than the fibre core during early stages of carbonization. In the current study, the maximum temperature used in LT carbonization is in the order of $800^{\circ} \mathrm{C}$, indicating that the difference in $I(D) / I(G)$ ratio from surface to central regions of fibres (shown in Figure 2c) is ascribed to the delay in the formation of well-established cross-linked structures in the core. However, with further progress in thermal treatment at high temperatures in the order of $1400^{\circ} \mathrm{C}$, the formation of planar structures could have taken place in the fibre core with the loss of nitrogen and other heteroatoms and finally led to the evolution of a uniform structure as shown in Figure 2c.

The storage modulus mapping in the fibre cross-sections is shown in Figure 3. In all the samples there is a clear distinction between the storage modulus values of epoxy (pink regions) and fibres (blue/green regions). From Figures $3 a$ to $3 c$ except baseline samples, all the other LT samples showed a variation in the distribution of storage modulus within the fibre

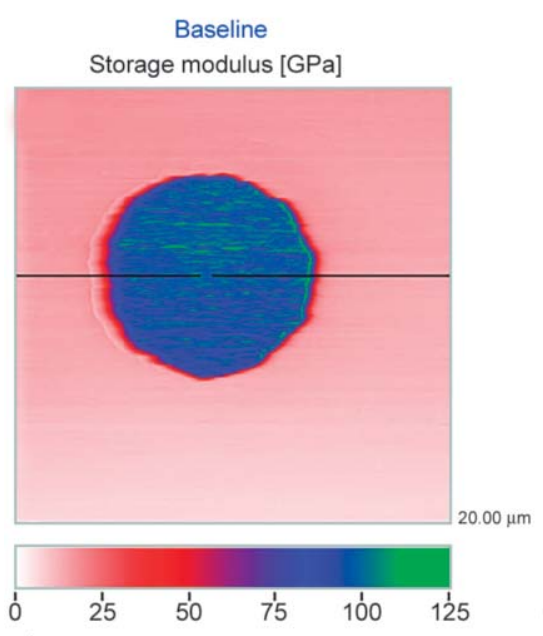

a)

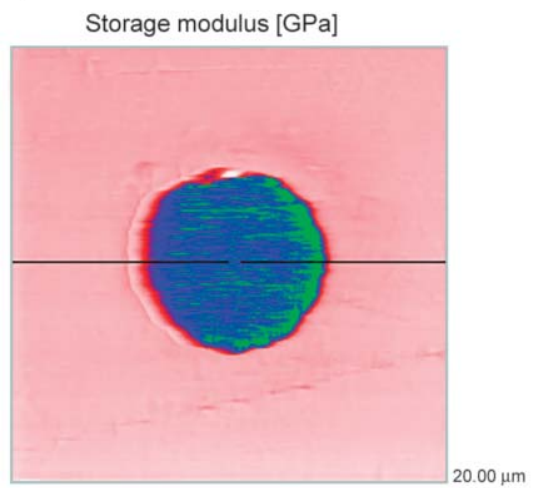

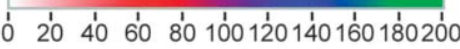

d)

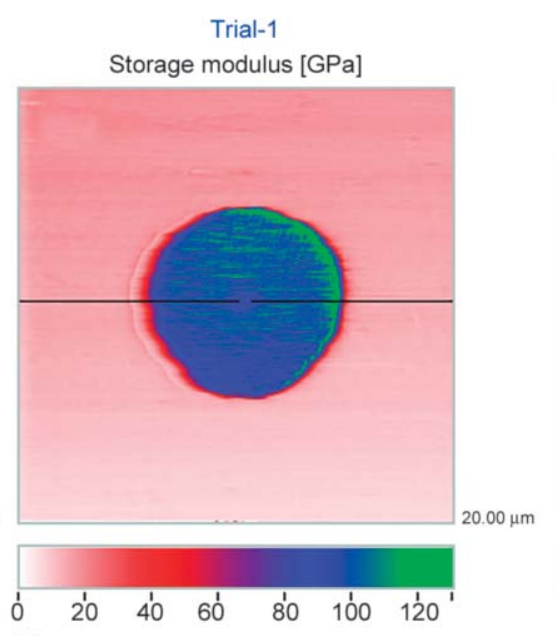

b)

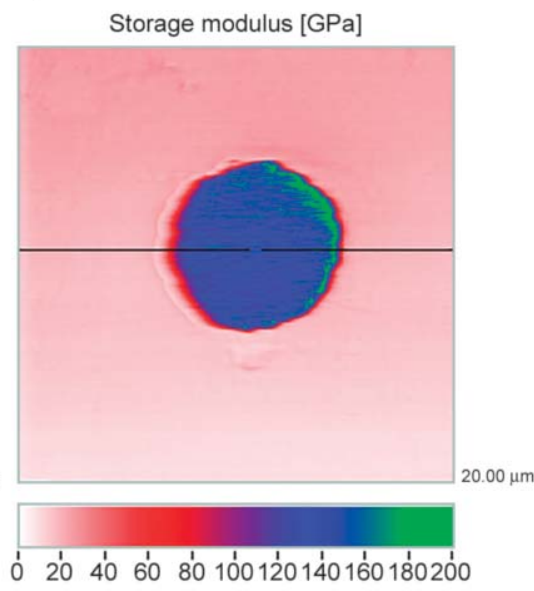

e)

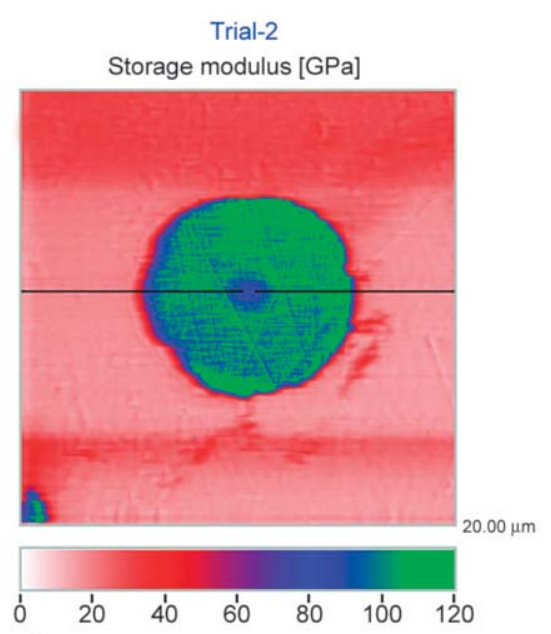

c)

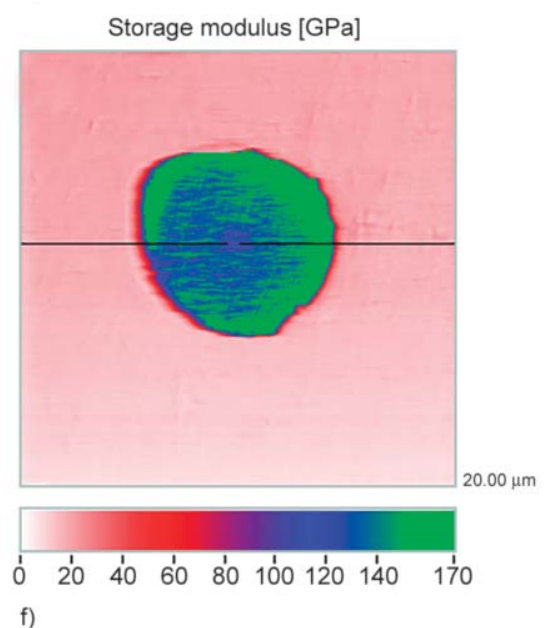

Figure 3. Storage modulus mapping in the carbon fibre cross-sections obtained from stabilized fibres treated at various temperature profiles. a) Baseline LT, b) Trial-1 LT, c) Trial-2 LT, d) Baseline HT, e) Trial-1 HT, f) Trial-2 HT samples. 
cross-section indicating the presence of radial heterogeneity/skin-core. However, after high temperature carbonization there is no storage modulus variation observed in carbon fibres from Baseline and Trial-1 samples. Interestingly, carbon fibre from Trial-2 sample still showed this property variation in the crosssection. The storage modulus is quantitatively plotted by performing a line scan across the fibre diameters as shown in Figure 4. Here our intention is to present the storage modulus variations within the samples rather than comparing the samples because these values are sensitive to surface finish. For example, in Figure 4, the values at the very edge of the fibres or at the fibre-epoxy interface are very high in some of the samples because of the inconsistencies in the surface morphology at the interface.

From Figure 4a, there is no skin-core in the Baseline LT sample when compared to Trial-1 and Trial-2 LT samples as shown in Figures $4 \mathrm{~b}$ and $4 \mathrm{c}$ which possess core regions having $\sim 17$ and $\sim 27 \mathrm{GPa}$ lower than the skin regions. From Figures $4 \mathrm{~d}$ and $4 \mathrm{e}$ there is no quantitative difference observed in the storage modulus in the fibre cross-sections of Baseline and Trial-1 HT samples. On the other hand, Trial-2 HT samples still exhibited a difference of at least $23 \mathrm{GPa}$ between skin and core regions of fibres as shown in Figure $4 \mathrm{f}$. Comparing Figure $2 \mathrm{c}$ and storage modulus distribution across the fibre diameter in Figure 4, it is interesting to note that, while the storage modulus is uniform in the Baseline sample compared to the other two samples, the $I(D) / I(G)$ ratio is similar to the other samples. Moreover, according to Raman studies shown in Figure 2c it is revealed that the structure is uniform throughout the HT carbon fibres, however, carbon fibres from Trial-2 shown in Figure 4e still show a significant skin-core effect. This indicates that with the progress in thermal treatment $\mathrm{sp}^{2}$ hybridized carbon network might have developed uniformly throughout the fibre cross-section with the evolution of heteroatoms during carbonization, however, it did not show a significant effect on the storage modulus variations. Moreover, two reasons can be given to explain this discrepancy; 1 . Storage modulus is sensitive to crystallinity of the material [52] rather than the formation of $\mathrm{sp}^{2}$ hybridized carbon network, 2. The orientation of the crystallites in the local areas might also have affected the storage modulus distribution. Based on these observations, it is interesting to further investigate the effect of the formation of the skin-core in the samples on the evolution of bulk tensile properties of carbon fibres.

\subsection{Influence of a stabilized fibre structure and presence of skin-core on the properties of carbon fibres}

Figure 5 shows the variation in density and tensile properties of resultant LT and HT carbon fibres with respect to stabilization temperature conditions. From
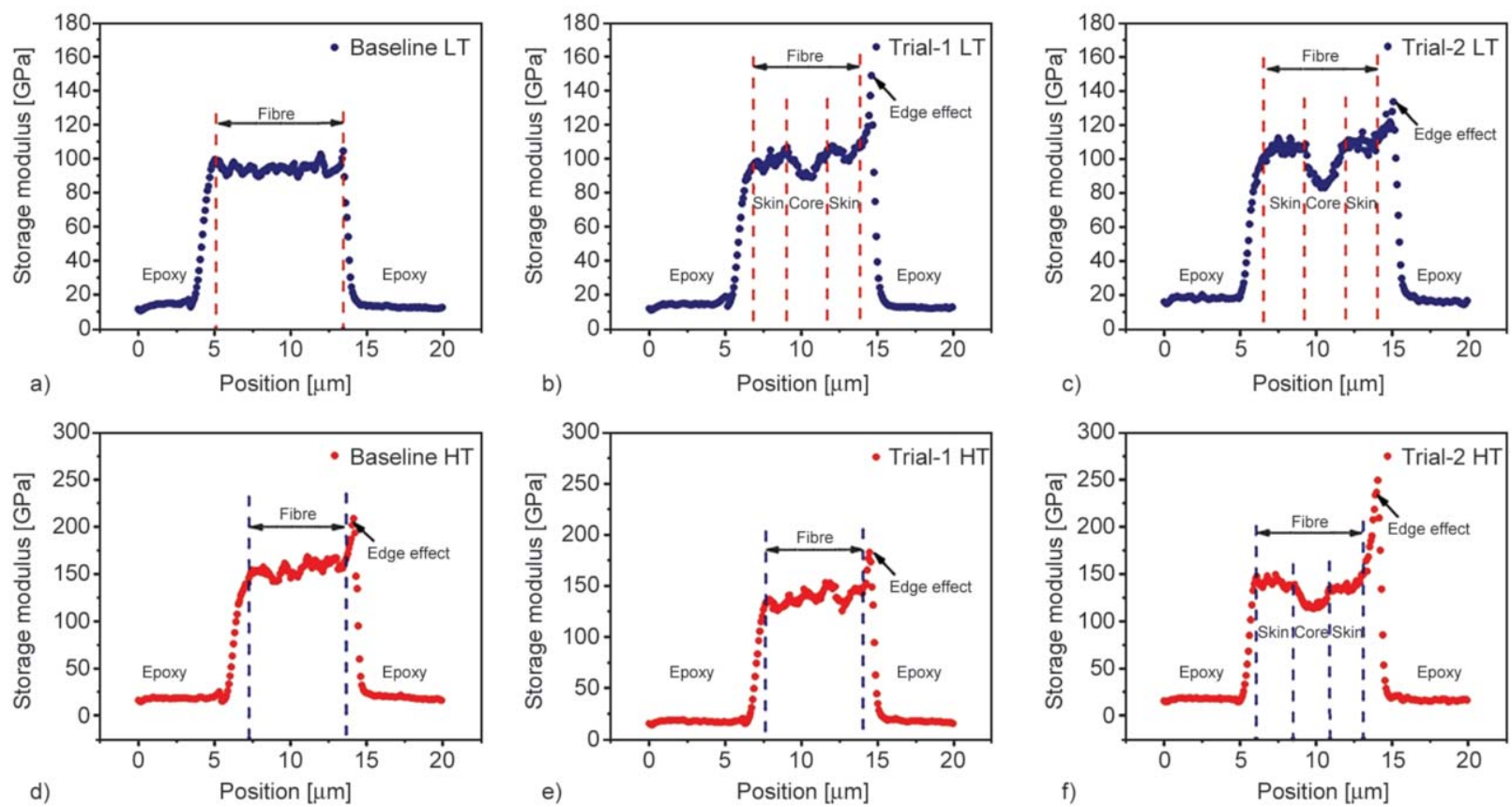

Figure 4. A line scan through the cross-section of respective carbon fibres (shown in Figure 3) shows the variation of storage modulus in fibres. 
Figure 5a there is an overall increase in the density of fibre samples from LT to HT. It is interesting to note that the density of carbon fibres processed from low density stabilized fibres is higher than the carbon fibres from high density stabilized fibres (compare Figure 1d and Figure 5a). Similar observations are made by Takaku et al. [47], it is proposed that the higher the density of stabilized fibres the higher the formation of micro voids in carbon fibres because of the evolution of non-carbon atoms that finally affects the density of carbon fibres. Sometimes formation of these micro voids may act as the defect sites and eventually influence the tensile strength.

Figure $5 \mathrm{~b}$ shows the tensile strength trends of carbon fibres where there is a dramatic increase in fibre strength from low temperature carbonization to high temperature carbonization due to the promotion of intermolecular crosslinking and the formation of carbon network during carbonization. The average tensile strengths of LT and HT samples of Trial-1 are in the order of 1.46 and 3.28 GPa which are higher than the Baseline (0.99 and 2.82 GPa) and Trial-2 (1.05 and $3.02 \mathrm{GPa}$ ) samples. Similar to tensile strength,

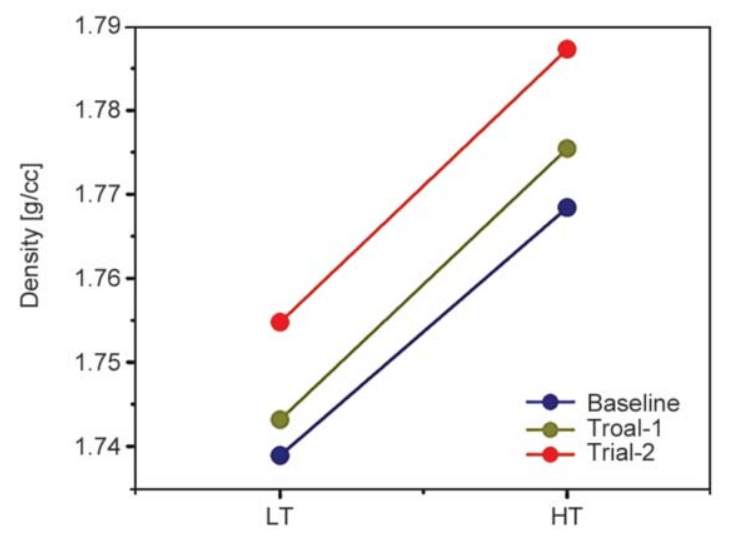

a)

Sample the average tensile moduli of LT and HT fibres of Trial-1 (97.3 and 239.36 GPa) are higher than the Baseline (95.3 and 232.2 GPa) and Trial-2 (91.2 and 232.06 GPa) samples. However, considering the standard deviations presented in Figures $5 b$ and $5 c$ there is no significant difference between the samples in terms of tensile properties. This is due to the evolution of similar structures in all the fibres after thermal stabilization irrespective of smaller or larger temperature increments in this stage.

Comparing Figures $4 \mathrm{a}$ to $4 \mathrm{f}$ and Figure $5 \mathrm{c}$ there is a difference between the tensile and storage modulus values especially in the case of HT carbon fibres. The possible reason could be the difference in the measurement mechanisms [43]. Interestingly, fibres with or without a skin-core have similar tensile properties which might be due to the existence of surface flaws in fibres. Moreover, under tensile loads the skin and the core regions deform uniformly therefore less possibility for the evolution of stress concentration areas. Tanaka et al. [53] mentioned that the strength of the carbon fibres is mainly controlled by uniform fracture toughness distribution along the fibre skin and surface

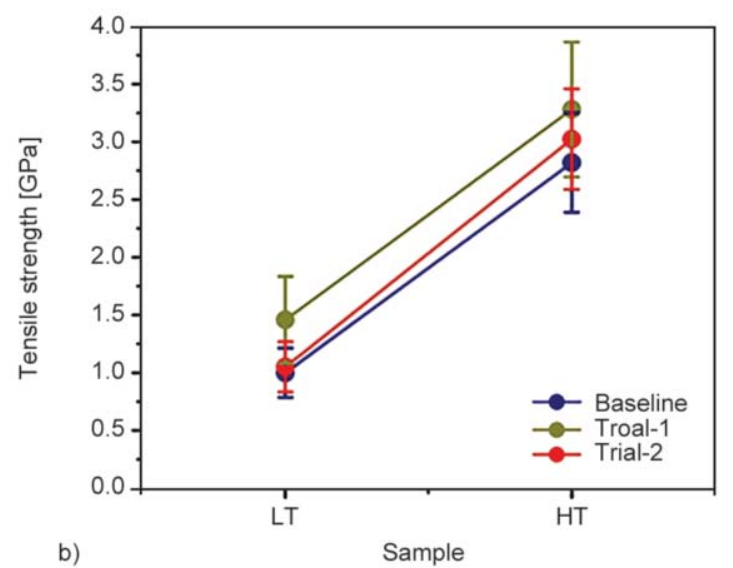

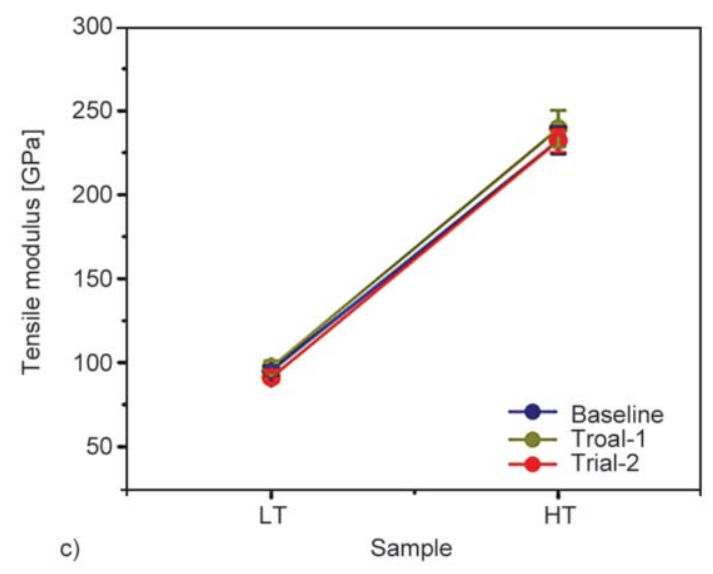

Figure 5. Variation in properties of carbon fibres with respect to thermal treatment a) density, b) tensile strength, c) tensile modulus. 
flaws rather than the skin-core effect. Hence, it is always suggested to develop a defect-free carbon fibre surface to achieve high performance fibres. Based on the current observations, it is conceivable that the skin-core formation is a mere effect rather than a defect. Given these observations it is possible to reduce the number of steps in thermal stabilization process without losing the properties of resultant carbon fibres. Hence this study also suggests a viable approach for rapid thermal stabilization and improve the throughput of carbon fibre processing.

\section{Conclusions}

The influence of the stabilization process conditions and formation of skin-core on the mechanical performance of resultant carbon fibres was systematically studied. It was identified that the final structure of stabilized fibres is strongly dependent on temperatures used at specific stages rather than the temperature profiles. Hence, with careful consideration of temperatures it is certainly possible to reduce the stabilization time. Irrespective of processing steps in stabilization, structural heterogeneity was observed in the cross-section of LT carbon fibres, however it had disappeared with further treatments at high temperatures. Interestingly, this structural difference was not correlated with the modulus mapping of respective carbon fibres as the storage modulus was possibly dependent on crystallinity and orientation of crystallites in local areas. Even though there was a skin-core difference in terms of storage modulus in the carbon fibres processed from rapid thermal stabilization conditions, it did not show any influence on the bulk properties of carbon fibres. The tensile properties of carbon fibres were mainly driven by the properties at the surface regions of fibres. Overall, the findings of this study revealed that the skin-core formation is merely an effect and it is certainly possible to stabilize PAN fibres in less dwell times by carefully considering reasonable temperature steps. This further reduces the processing times and improves throughput for carbon fibre processing and provides a pathway to reduce the final cost of carbon fibres which is of high importance to industries such as automotive.

\section{Acknowledgements}

We would like to thank operational team for their support in processing carbon fibres using research line at Carbon Nexus. We also thank Mr. Mathews Joseph for assisting in tensile testing of fibres. This research was supported by the Australian Research Council World Class Future Fiber Industry Transformation Research Hub (IH140100018) and the Australian Research Council Training Centre for Lightweight Automotive Structures (ATLAS).

\section{References}

[1] Nunna S., Maghe M., Fakhrhoseini S. M., Polisetti B., Naebe M.: A pathway to reduce energy consumption in the thermal stabilization process of carbon fiber production. Energies, 11, 1145/1-1145/10 (2018).

https://doi.org/10.3390/en11051145

[2] Khayyam H., Mousa Fakhrhoseini S., Church J. S., Milani A. S., Bab-Hadiashar A., Jazar R., Naebe M.: Predictive modelling and optimization of carbon fiber mechanical properties through high temperature furnace. Applied Thermal Engineering, 125, 1539-1554 (2017). https://doi.org/10.1016/j.applthermaleng.2017.06.071

[3] Bafekrpour E., Simon G. P., Naebe M., Habsuda J., Yang C., Fox B.: Preparation and properties of composition-controlled carbon nanofiber/phenolic nanocomposites. Composites Part B: Engineering, 52, 120126 (2013).

https://doi.org/10.1016/j.compositesb.2013.03.007

[4] Ellringmann T., Wilms C., Warnecke M., Seide G., Gries T.: Carbon fiber production costing: A modular approach. Textile Research Journal, 86, 178-190 (2016). https://doi.org/10.1177/0040517514532161

[5] Oroumei A., Fox B., Naebe M.: Thermal and rheological characteristics of biobased carbon fiber precursor derived from low molecular weight organosolv lignin. ACS Sustainable Chemistry and Engineering, 3, 758769 (2015).

https://doi.org/10.1021/acssuschemeng.5b00097

[6] Qu W., Xue Y., Gao Y., Rover M., Bai X.: Repolymerization of pyrolytic lignin for producing carbon fiber with improved properties. Biomass and Bioenergy, 95, 19--26 (2016). https://doi.org/10.1016/j.biombioe.2016.09.013

[7] Oroumei A., Lynch P., Tobin M., Naebe M.: Synchrotron x-ray scattering and IR-mapping studies of wetspun lignin-derived carbon fibre precursor. Composites Science and Technology, 163, 151-161 (2018). https://doi.org/10.1016/j.compscitech.2018.05.026

[8] Oroumei A., Naebe M.: Mechanical property optimization of wet-spun lignin/polyacrylonitrile carbon fiber precursor by response surface methodology. Fibers and Polymers, 18, 2079-2093 (2017).

https://doi.org/10.1007/s12221-017-7363-9 
[9] Yoo S. H., Park S., Park Y., Lee D., Joh H-I., Shin I., Lee S.: Facile method to fabricate carbon fibers from textile-grade polyacrylonitrile fibers based on electronbeam irradiation and its effect on the subsequent thermal stabilization process. Carbon, 118, 106-113 (2017). https://doi.org/10.1016/j.carbon.2017.03.039

[10] Byrne N., Setty M., Blight S., Tadros R., Ma Y., Sixta H., Hummel M.: Cellulose-derived carbon fibers produced via a continuous carbonization process: Investigating precursor choice and carbonization conditions. Macromolecular Chemistry and Physics, 217, 2517-2524 (2016).

https://doi.org/10.1002/macp.201600236

[11] Spörl J. M., Beyer R., Abels F., Cwik T., Müller A., Hermanutz F., Buchmeiser M. R.: Cellulose-derived carbon fibers with improved carbon yield and mechanical properties. Macromolecular Materials and Engineering, 302, 1700195/1-1700195/10 (2017).

https://doi.org/10.1002/mame.201700195

[12] Stanger R., Tran Q. A., Browne M., Lucas J., Naebe M., Height M., Wall T.: Evaluating the thermal extrusion behavior of a coking coal for direct carbon fiber production. Energy and Fuels, 32, 4528-4537 (2018). https://doi.org/10.1021/acs.energyfuels. $7 b 03192$

[13] Badii K., Church J. S., Golkarnarenji G., Naebe M., Khayyam H.: Chemical structure based prediction of PAN and oxidized PAN fiber density through a non-linear mathematical model. Polymer Degradation and Stability, 131, 53-61 (2016).

https://doi.org/10.1016/j.polymdegradstab.2016.06.019

[14] Ghorpade R. V., Cho D. W., Hong S. C.: Effect of controlled tacticity of polyacrylonitrile (co)polymers on their thermal oxidative stabilization behaviors and the properties of resulting carbon films. Carbon, 121, 502 -511 (2017).

https://doi.org/10.1016/j.carbon.2017.06.015

[15] Nunna S., Naebe M., Hameed N., Fox B. L., Creighton C.: Evolution of radial heterogeneity in polyacrylonitrile fibres during thermal stabilization: An overview. Polymer Degradation and Stability, 136, 20-30 (2017). https://doi.org/10.1016/j.polymdegradstab.2016.12.007

[16] Krishnan G. S., Thomas P., Murali N.: Synthesis, characterization, and thermo-mechanical properties of poly (acrylonitrile-co-2,3-dimethyl-1,3-butadiene-co-itaconic acid) as carbon fibre polymer precursors. RSC Advances, 6, 6182-6190 (2016).

https://doi.org/10.1039/c5ra24185e

[17] Golkarnarenji G., Naebe M., Badii K., Milani A. S., Jazar R. N., Khayyam H.: Production of low cost carbon-fiber through energy optimization of stabilization process. Materials, 11, 385/1-385/13 (2018). https://oi.org/10.3390/ma11030385

[18] Santhana Krishnan G., Thomas P., Naveen S., Murali N.: Molecular and thermal studies of carbon fiber precursor polymers with low thermal-oxidative stabilization characteristics. Journal of Applied Polymer Science, 135, 46381/1-46381/15 (2018).

https://doi.org/10.1002/app.46381
[19] Nunna S., Creighton C., Hameed N., Naebe M., Henderson L. C., Setty M., Fox B. L.: Radial structure and property relationship in the thermal stabilization of PAN precursor fibres. Polymer Testing, 59, 203-211 (2017). https://doi.org/10.1016/j.polymertesting.2017.02.006

[20] Xue Y., Liu J., Lian F., Liang J.: Effect of the oxygeninduced modification of polyacrylonitrile fibers during thermal-oxidative stabilization on the radial microcrystalline structure of the resulting carbon fibers. Polymer Degradation and Stability, 98, 2259-2267 (2013). https://doi.org/10.1016/j.polymdegradstab.2013.08.016

[21] Zhao R-X., Sun P-F., Liu R-J., Ding Z-H., Li X-S., Liu X-Y., Zhao X-D., Gao Z-M.: Influence of heating procedures on the surface structure of stabilized polyacrylonitrile fibers. Applied Surface Science, 433, 321-328 (2018).

https://doi.org/10.1016/j.apsusc.2017.09.252

[22] Khayyam H., Naebe M., Bab-Hadiashar A., Jamshidi F., Li Q., Atkiss S., Buckmaster D., Fox B.: Stochastic optimization models for energy management in carbonization process of carbon fiber production. Applied Energy, 158, 643-655 (2015). https://doi.org/10.1016/j.apenergy.2015.08.008

[23] Hameed N., Sharp J., Nunna S., Creighton C., Magniez K., Jyotishkumar P., Salim N. V., Fox B.: Structural transformation of polyacrylonitrile fibers during stabilization and low temperature carbonization. Polymer Degradation and Stability, 128, 39-45 (2016). https://doi.org/10.1016/j.polymdegradstab.2016.02.029

[24] Khayyam H., Naebe M., Zabihi O., Zamani R., Atkiss S., Fox B.: Dynamic prediction models and optimization of polyacrylonitrile (PAN) stabilization processes for production of carbon fiber. IEEE Transactions on Industrial Informatics, 11, 887-895 (2015). https://doi.org/10.1109/TII.2015.2434329

[25] Hao J., Liu Y., Lu C.: Effect of acrylonitrile sequence distribution on the thermal stabilization reactions and carbon yields of poly(acrylonitrile-co-methyl acrylate). Polymer Degradation and Stability, 147, 89-96 (2018). https://doi.org/10.1016/j.polymdegradstab.2017.11.010

[26] Maghe M., Creighton C., Henderson L. C., Huson M. G., Nunna S., Atkiss S., Byrne N., Fox B. L.: Using ionic liquids to reduce energy consumption for carbon fibre production. Journal of Materials Chemistry A, 4, 16619 16626 (2016). https://doi.org/10.1039/C6TA06842A

[27] Fakhrhoseini S. M., Khayyam H., Naebe M.: Chemically enhanced wet-spinning process to accelerate thermal stabilization of polyacrylonitrile fibers. Macromolecular Materials and Engineering, 303, 1700557/11700557/8 (2018).

https://doi.org/10.1002/mame.201700557

[28] Xue Y., Liu J., Liang J.: Correlative study of critical reactions in polyacrylonitrile based carbon fiber precursors during thermal-oxidative stabilization. Polymer Degradation and Stability, 98, 219-229 (2013). https://doi.org/10.1016/j.polymdegradstab.2012.10.018 
[29] Arbab S., Zeinolebadi A.: Quantitative analysis of the effects of comonomers and heating conditions on the stabilization reactions of polyacrylonitrile fibers as carbon fiber precursors. Polymer Degradation and Stability, 139, 107-116 (2017).

https://doi.org/10.1016/j.polymdegradstab.2017.04.003

[30] Arbab S., Mirbaha H., Zeinolebadi A., Nourpanah P.: Indicators for evaluation of progress in thermal stabilization reactions of polyacrylonitrile fibers. Journal of Applied Polymer Science, 131, 40343/1-40343/8 (2014). https://doi.org/10.1002/APP.40343

[31] Wang J., Hu L., Yang C., Zhao W., Lu Y.: Effects of oxygen content in the atmosphere on thermal oxidative stabilization of polyacrylonitrile fibers. RSC Advances, 6, 73404-73411 (2016). https://doi.org/10.1039/c6ra15308a

[32] Golkarnarenji G., Naebe M., Badii K., Milani A. S., Jazar R. N., Khayyam H.: Support vector regression modelling and optimization of energy consumption in carbon fiber production line. Computers and Chemical Engineering, 109, 276-288 (2018).

https://doi.org/10.1016/j.compchemeng.2017.11.020

[33] Nunna S., Creighton C., Fox B. L., Naebe M., Maghe M., Tobin M. J., Bambery K., Vongsvivut J., Hameed N.: The effect of thermally induced chemical transformations on the structure and properties of carbon fibre precursors. Journal of Materials Chemistry A, 5, 7372 7382 (2017).

https://doi.org/10.1039/C7TA01022B

[34] Nunna S., Naebe M., Hameed N., Creighton C., Naghashian S., Jennings M. J., Atkiss S., Setty M., Fox B. L.: Investigation of progress of reactions and evolution of radial heterogeneity in the initial stage of thermal stabilization of PAN precursor fibres. Polymer Degradation and Stability, 125, 105-114 (2016).

https://doi.org/10.1016/j.polymdegradstab.2016.01.008

[35] Lv M-Y., Ge H-Y., Chen J.: Study on the chemical structure and skin-core structure of polyacrylonitrilebased fibers during stabilization. Journal of Polymer Research, 16, 513-517 (2008).

https://doi.org/10.1007/s10965-008-9254-7

[36] Liu X., Zhu C., Guo J., Liu Q., Dong H., Gu Y., Liu R., Zhao N., Zhang Z., Xu J.: Nanoscale dynamic mechanical imaging of the skin-core difference: From PAN precursors to carbon fibers. Materials Letters, 128, 417 420 (2014).

https://doi.org/10.1016/j.matlet.2014.04.176

[37] Guo X., Cheng Y., Fan Z., Feng Z., He L., Liu R., Xu J.: New insights into orientation distribution of high strength polyacrylonitrile-based carbon fibers with skin-core structure. Carbon, 109, 444-452 (2016). https://doi.org/10.1016/j.carbon.2016.08.022

[38] Li D., Lu C., Wu G., Yang Y., An F., Feng Z., Li X.: Structural heterogeneity and its influence on the tensile fracture of PAN-based carbon fibers. RSC Advances, 4, 60648-60651 (2014). https://oi.org/10.1039/c4ra08530b
[39] Kobayashi T., Sumiya K., Fukuba Y., Fujie M., Takahagi T., Tashiro K.: Structural heterogeneity and stress distribution in carbon fiber monofilament as revealed by synchrotron micro-beam X-ray scattering and microRaman spectral measurements. Carbon, 49, 1646-1652 (2011).

https://doi.org/10.1016/j.carbon.2010.12.048

[40] Collins G. L., Thomas N. W., Williams G. E.: Kinetic relationships between heat generation and nitrile consumption in the reaction of poly(acrylonitrile) in air at $265^{\circ} \mathrm{C}$. Carbon, 26, 671-679 (1988).

https://doi.org/10.1016/0008-6223(88)90070-X

[41] Karacan I., Erdogan G.: The influence of thermal stabilization stage on the molecular structure of polyacrylonitrile fibers prior to the carbonization stage. Fibers and Polymers, 13, 295-302 (2012).

https://doi.org/10.1007/s12221-012-0295-5

[42] Zlotnikov I., Zolotoyabko E., Fratzl P.: Nano-scale modulus mapping of biological composite materials: Theory and practice. Progress in Materials Science, 87, 292320 (2017). https://doi.org/10.1016/j.pmatsci.2017.03.002

[43] Gu Y., Li M., Wang J., Zhang Z.: Characterization of the interphase in carbon fiber/polymer composites using a nanoscale dynamic mechanical imaging technique. Carbon, 48, 3229-3235 (2010).

https://doi.org/10.1016/j.carbon.2010.05.008

[44] Arbab S., Zeinolebadi A.: A procedure for precise determination of thermal stabilization reactions in carbon fiber precursors. Polymer Degradation and Stability, 98, 2537-2545 (2013).

https://doi.org/10.1016/j.polymdegradstab.2013.09.014

[45] Ko T-H., Lin C-H., Ting H-Y.: Structural changes and molecular motion of polyacrylonitrile fibers during pyrolysis. Journal of Applied Polymer Science, 37, 553566 (1989).

https://doi.org/10.1002/app.1989.070370220

[46] Rahaman M. S. A., Ismail A. F., Mustafa A.: A review of heat treatment on polyacrylonitrile fiber. Polymer Degradation and Stability, 92, 1421-1432 (2007). https://doi.org/10.1016/j.polymdegradstab.2007.03.023

[47] Takaku A., Hashimoto T., Miyoshi T.: Tensile properties of carbon fibers from acrylic fibers stabilized under isothermal conditions. Journal of Applied Polymer Science, 30, 1565-1571 (1985). https://doi.org/10.1002/app.1985.070300421

[48] Huson M. G., Church J. S., Kafi A. A., Woodhead A. L., Khoo J., Kiran M. S. R. N., Bradby J. E., Fox B. L.: Heterogeneity of carbon fibre. Carbon, 68, 240-249 (2014). https://doi.org/10.1016/j.carbon.2013.10.084

[49] Melanitis N., Tetlow P. L., Galiotis C.: Characterization of PAN-based carbon fibres with laser Raman spectroscopy. Journal of Materials Science, 31, 851-860 (1996). https://doi.org/10.1007/bf00352882 
[50] Fitzer E., Frohs W., Heine M.: Optimization of stabilization and carbonization treatment of PAN fibres and structural characterization of the resulting carbon fibres. Carbon, 24, 387-395 (1986).

https://doi.org/10.1016/0008-6223(86)90257-5

[51] Mittal J., Konno H., Inagaki M., Bahl O. P.: Denitrogenation behavior and tensile strength increase during carbonization of stabilized PAN fibers. Carbon, 36, 1327 1330 (1998).

https://doi.org/10.1016/S0008-6223(98)00113-4
[52] Batista N. L., Olivier P., Bernhart G., Rezende M. C., Botelho E. C.: Correlation between degree of crystallinity, morphology and mechanical properties of PPS/carbon fiber laminates. Materials Research, 19, 195-201 (2016). https://doi.org/10.1590/1980-5373-mr-2015-0453

[53] Tanaka F., Okabe T., Okuda H., Kinloch I. A., Young R. J.: Factors controlling the strength of carbon fibres in tension. Composites Part A: Applied Science and Manufacturing, 57, 88-94 (2014).

https://doi.org/10.1016/j.compositesa.2013.11.007 